\section{Early turbulence and drag reduction phenomena in larger pipes}

SoLUTIONS of certain high molecular weight polymers have been shown to exhibit the phenomena of both early turbulence ${ }^{1-7}$ and drag reduction ${ }^{4,5,8}$ depending on whether the measurements were made under laminar flow conditions for the former case or under turbulent flow conditions for the latter. In general, early turbulence has been observed only in capillary tube flows while drag reduction has been observed in a variety of flow geometries, the only requirement being a developing or developed turbulent flow field.

A correspondence of sorts between early turbulence and drag reduction was surmised earlier ${ }^{9}$ and was also strongly implied by capillary tube measurements where a continuous transition between early turbulence onset points and drag reduction onset had been observed. A close relationship between the two phenomena was therefore suggested ${ }^{5}$. Specifically, the non-Newtonian onset point (either early turbulence or drag reduction) for 1 p.p.m. solutions of Polyox coagulant in a series of salt solutions were found to be described by the following empirical relationship in these capillary flows

$$
\tau^{*}=(78.7) /(1-1.39 M)
$$

where $\tau^{*}$ is the non-Newtonian onset point and $M$ the molarity of the magnesium sulphate salt solution.

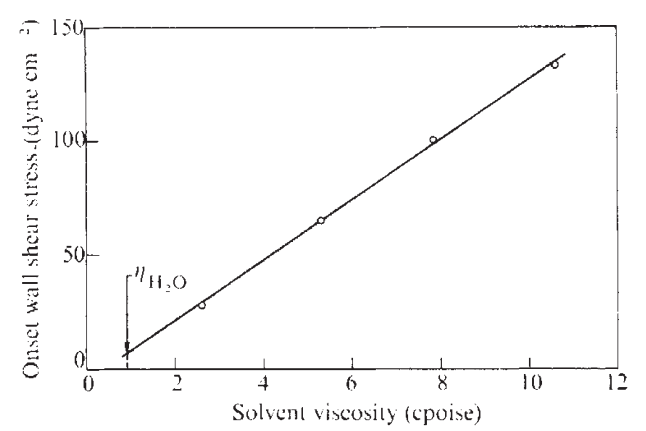

Fig. 1 Onset of early turbulence for 100 p.p.m. WSR-205 solutions in glycerine-water mixtures. Pipe diameter, $0.553 \mathrm{~cm}$.

The suggestion has been made ${ }^{2}$ that early turbulence might also be observed for flows in larger diameter tubes provided sufficiently high wall shear stresses could be attained in the laminar flow regimes. This hypothesis was confirmed by subsequent experiments in larger diameter pipes with drag reducing additives dissolved in water-glycerine mixture ${ }^{6,7}$; the glycerine serving the function of significantly altering the solution viscosity, thus providing the needed higher wall shear stresses in laminar flow conditions. Figure 1 shows the variation of the onset wall shear stress for early turbulence with solvent viscosity for 100 p.p.m. WSR-205 solutions in glycerine-water mixtures in a $0.553 \mathrm{~cm}$ pipe. The plot is essentially linear over the range of solvent viscosities chosen. The linear relationship suggests that an extrapolation might justifiably be made to the pure water case. Thus, a hypothetical value of 7.4 dyne $\mathrm{cm}^{-2}$ is obtained for the onset of early turbulence in this particular pipe for the water case had the flow not undergone transition to the turbulent regime. Data ${ }^{8}$ are also available for the same WSR205 sample under turbulent flow conditions in pure water. Figure 2 shows a plot of the drag reduction onset wall shear stress against the log concentration. Although 100 p.p.m. WSR-205 had not been studied in the earlier work a short extrapolation

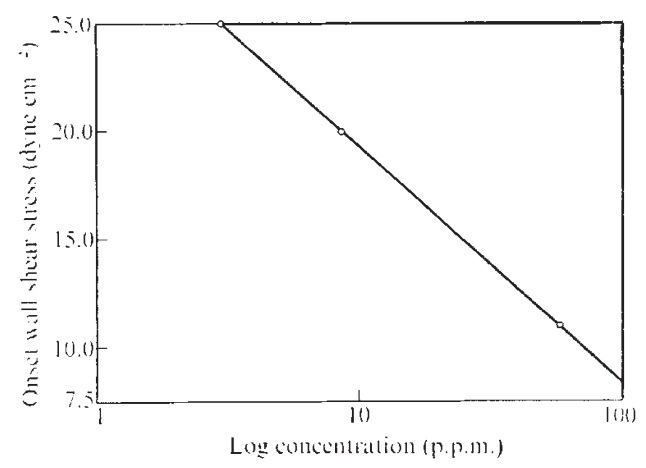

Fig. 2 Onset of drag reduction against $\log$ concentration for WSR-205 solutions in turbulent flow. Pipe diameter, $0.660 \mathrm{~cm}$.

of the linear plot in Fig. 2 to the 100 p.p.m. value yields an onset wall shear stress for drag reduction of approximately 8 dyne $\mathrm{cm}^{-2}$. Although both sets of data rely on short extrapolations this additional evidence does seem to support earlier claims $s^{4,6,9}$ that drag reduction and early turbulence are somewhat related phenomena.

$\begin{array}{ll} & \text { R. J. HANSEN } \\ \text { Naval Research Laboratory, } & \text { R. C. LITTLE }\end{array}$

Washington, DC 20375

Received August 23; revised October 23, 1974.

1 Ram, A., and Tamir, A., J. appl. polym. Sci., 8, 2751 (1964).

2 Little, R. C., NRL Memo Rep. 1957, (Clearinghouse, Defense Documentation Center Report No. AD-684770, January 1969).

3 Jones, W. M., and Maddock, J. L., J. Phys. D., 2, 797 (1969).

4 Little, R. C., and Wiegard, M., J. appl. polym. Sci., 14, 409 (1970).

${ }_{5}$ Little, R. C., J. appl. polym. Sci., 15, 3117 (1971).

6 Forame, P. C., Hansen, R. J., and Little, R. C., AIChE J., 18, 213 (1972).

7 Hansen, R. J., Little, R. C., and Forame, P. C., chem. Engng, Japan, 6, 310 (1973).

8 Hansen, R. J., and Little, R. C., Chem. Engng Prog. Symp. 67, 93 (1971).

9 Fabula, A. G., Lumley, J. L., and Taylor, W. D., Modern Developments in the Mechanics of Continua, 145 (Academic Press, New York, 1966).

\section{Preserved amino acids from silicified protein in fossil Radiolaria}

THE discovery of amino acids in fossils ${ }^{1}$ has stimulated a wide range of biochemical studies ${ }^{2,3}$ over the past $20 \mathrm{yr}$ with implications for evolution, geochronology, and biomineralisation. One productive line of evolutionary investigation has been the analysis of calcified protein from Recent shells of calcareous invertebrates such as molluscs ${ }^{4,5}$ and plank tonic Foraminifera ${ }^{6,7}$. Results indicate that the amino acid composition is speciesspecific and varies in a systematic manner which parallels morphology. Moreover, data from extinct 18-Myr-old Foraminifera suggest that the technique can be applied directly to the deepsea fossil record for establishing phylogenetic affinities ${ }^{6,7}$. Virtually nothing is known, however, of the nature of the organic matrices which may exist in fossil skeletons composed of silicia rather than calcium carbonate. Amino acid data from this study are therefore believed to be the first evidence reported for the presence and diagenesis of silicified protein in the fossil record.

Radiolaria, important contributors to the siliceous ooze characteristic of Equatorial Pacific and Antarctic regions, were 